\title{
Биофлавоноиды \\ в лечении пациентов \\ с сахарным диабетом \\ 2-го типа и церебральным атеросклерозом
}

\section{Н.Д. Тронько', С.М. Кузнецова ${ }^{2}$, М.С. Черская ${ }^{1}$}

1 ГУ «Институт эндокринологии и обмена веществ им. В.П. Комиссаренко НАМН Украины»

2 ГУ «Институт геронтологии им. Д.Ф. Чеботарева НАМН Украины»

Резюме. Цель работы - комплексная оценка влияния кверцетина на функциональное состояние центральной нервной и сердечно-сосудистой систем у больных ишемическим инсультом (ИИ) и сахарным диабетом 2-го типа (СД2) в восстановительный период. Материал и методы. В клинике ГУ «Институт геронтологии им. Д.Ф. Чеботарева НАМН Украины» проведено открытое пилотное когортное проспективное клиническое исследование, которое включало 30 больных, перенесших атеротромботический ишемический инсульт в ка-

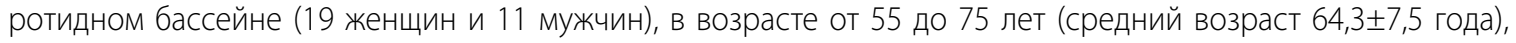
треть из них имели в анамнезе СД2. До и после курсового приема препарата кверцетин больным проводили комплексное клинико-неврологическое и нейропсихологическое обследование, исследование мозгового кровотока методом ультразвукового дуплексного сканирования экстра- и интракраниальных отделов магистральных артерий головы и шеи, электрокардиографию с оценкой вариабельности ритма сердца. Все больные получали кверцетин (лиофилизат для приготовления раствора для инъекций (комплекс кверцетина с повидоном) в дозе 0,5 г в сутки в течение 10 дней. Для приготовления раствора для внутривенного введения препарат растворяли в 100 мл изотонического раствора $\mathrm{NaCl}$ и вводили внутривенно капельно в течение 15-20 минут 1 раз в день. Результаты. У больных с левополушарным инсультом кверцетин оказывал более выраженное влияние на структуру биоэлектрической активности головного мозга и церебральную гемодинамику, чем у больных с правополушарной локализацией ИИ. У больных, перенесших ИИ, кверцетин улучшал психоэмоциональные и мнестические функции за счет положительной реорганизации биоэлектрической активности головного мозга, улучшения церебральной гемодинамики и гармонизации симпатического и па-

\footnotetext{
* Адреса для листування (Correspondence): ДУ «Інститут ендокринології та обміну речовин ім. В.П. Комісаренка НАМН України», вул. Вишгородська, 69, м. Київ, 04114

Україна. E-mail: zdovado@ukr.net

(с) Н.Д. Тронько, С.М. Кузнечова, М.С. Черская
} 
Оригінальні дослідження

расимпатического звеньев вегетативной нервной системы. Выводы. Корригирующее влияние кверцетина на функциональное состояние мозга и сердца дает основание рекомендовать применение препарата в системе реабилитации больных, перенесших ишемический инсульт.

Ключевые слова: ишемический инсульт, сахарный диабет 2-го типа, функциональное состояние нервной и сердечно-сосудистой системы, кверцетин.

Борьба с сердечно-сосудистыми заболеваниями является одним из приоритетных направлений медицины, поскольку, имея общую структуру факторов риска, они обусловливают большую долю смертности в популяции [1] и высокий процент инвалидизации населения $[8,9]$. Сосудистые заболевания головного мозга являются одной из наиболее распространенных причин инвалидизации. В связи с этим проблема реабилитации больных инсультом чрезвычайно актуальна. Для разработки эффективных методов реабилитации необходимы знания о фундаментальных патогенетических механизмах, определяющих функционально-морфологическое и биохимическое состояние мозга у больных в различные периоды инсульта [5].

Важным достижением экспериментальной и клинической медицины в последние десятилетия является получение новых данных о молекулярно-биохимической структуре ишемического каскада, определяющей патогенетические механизмы формирования и течения острых и хронических заболеваний мозга и сердца. Знания структуры ишемического каскада позволяют разработать эффективные пути фармакологической коррекции патогенетических нарушений, характерных для наиболее распространенных сердечно-сосудистых заболеваний - инсульта, инфаркта миокарда, сердечной недостаточности. Пусковым механизмом ишемического каскада является энергетический дефицит, который в нейронах «включает» так называемый глутамат-кальциевый каскад, к стадии «индукции» которого относят деполяризацию мембран, нарушения активного ионного транспорта и компенсаторный избыточный выброс возбуждающих нейротрансмиттеров (глутамата и аспартата) [5, 6]. В миокардиоцитах ишемический каскад также характеризуется уменьшением продукции креатинфосфата и АТФ, снижением рН и увеличением продукции недоокисленных продуктов в тканях. Нарушение АТФ-зависимого трансмембранного ионного транспорта - уменьшение активности таких ферментов, как Na-K-АТФаза, Ca-Mg-АТФаза, приводит к накоплению внутриклеточного кальция - основного триггера конечных механизмов каскада (оксидативный стресс, дисбаланс цитокинов, локальное воспаление, микроциркуляторные клеточные реакции) $[2,7,9]$.

Таким образом, церебральная и кардиальная ишемия сопровождаются активацией патобиохимических и молекулярных механизмов, обусловливающих структурно-морфологические изменения в нейронах, глии и миокардиоцитах. Эффективным стратегическим направлением коррекции острой и хронической ишемии мозга и сердца является воздействие на различные звенья ишемического каскада. В последние годы в терапии сердечно-сосудистых заболеваний большое внимание уделяют препаратам с мультимодальным действием. К таким препаратам относится Корвитин ${ }^{\circledR}$ - растворимая форма биофлаваноида кверцетина. Корвитин ${ }^{\circledR}$ оказывает антиоксидантное, иммуномодулирующее, мембраностабилизирующее, кардиопротекторное, антигипоксическое и противовоспалительное действие, усиливает репаративные процессы. Наиболее детально изучены кардиопротекторные механизмы действия Корвитина, что послужило основанием широкого использования кверцетина в клинике острого инфаркта миокарда по схеме, разработанной А.Н. Пархоменко и соавт. [4,6].

Для Корвитина характерно церебропротекторное и нейропротекторное действие, обусловленное снижением глутаматной эксайтотоксичности, внутриклеточной гиперкальциемии и регуляцией синтеза оксида азота [10]. Антиатерогенный эффект кверцетина 
осуществляется за счет снижения активности перекисного окисления липидов и ингибирования процессов липопероксидации [3, 4]. Кверцетин осуществляет интенсивное торможение катаболических ферментов, нарушающих структуру фосфолипидов клеточных мембран при ишемии и реперфузии: киназ (протеинкиназы C, протеинтирозинкиназы, фосфолипазы, липоксигеназы, циклооксигеназы), РНК- и ДНК-полимеразы, лактатдегидрогеназы и целого ряда других, что определяет его мембраностабилизирующее действие [8, 12]. Мембраностабилизирующее действие кверцетина проявляется и в способности инактивировать свободные радикалы, ингибировать образование супероксидрадикалов, увеличивать эффективность антиоксидантной защиты [2, 3].

Кверцетин обладает сосудорасширяющим эффектом за счет снижения концентрации арахидоновой кислоты и лейкотриена С4, которые оказывают мощное сосудосуживающее действие, ухудшают коронарный кровоток [3]. Кверцетин также тормозит агрегацию тромбоцитов, образование тромбоксана $\mathrm{B}_{4}$, что определяет его антитромботическое действие [2, 6]. Результаты клинических и экспериментальных исследований свидетельствуют о терапевтической эффективности кверцетина при инфаркте миокарда и в острый период ишемического инсульта [5, 7].

Итак, кверцетин имеет мультимодальный спектр фармакологических эффектов: антиоксидантный, антигипоксантный, противовоспалительный, мембраностабилизирующий, активирует энергосинтезирующие функции митохондрий. Воздействие кверцетина на основные звенья ишемического биохимического каскада определяет перспективность его применения в лечении сосудистых заболеваний сердца и мозга.

Цель работы - комплексная оценка влияния кверцетина на функциональное состояние центральной нервной и сердечно-сосудистой систем у больных ишемическим инсультом (ИИ) и сахарным диабетом 2-го типа (СД2) в восстановительный период.

\section{Материал и методы}

В клинике ГУ «Институт геронтологии имени Д.Ф. Чеботарева НАМН Украины» проведено открытое пилотное когортное проспективное клиническое исследование, которое включало 30 больных, перенесших атеротромботический ишемический инсульт в каротидном бассейне (19 женщин и 11 мужчин), в возрасте от 55 до

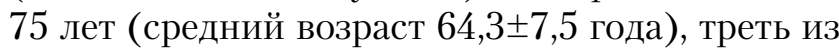
них имели в анамнезе СД2. Диагноз ИИ устанавливали на основании данных клинико-неврологического обследования и МРТ в соответствии с рекомендациями ВОЗ. Критерии исключения из исследования: сердечная недостаточность III-IV ФК по NYHA, инфаркт миокарда, приобретенные пороки сердца, наличие сопутствующих декомпенсированных соматических заболеваний. До и после курсового приема препарата Корвитин ${ }^{\circledR}$ больным проводили комплексное клинико-неврологическое и нейропсихологическое обследование, включающее:

- оценку общей функциональной независимости (индекс Бартел);

- оценку психоэмоционального состояния (тест «Запоминание 10 слов» А.Р. Лурия, тест Мюнстерберга);

- анализ биоэлектрической активности головного мозга по данным электроэнцефалографии на аппарате Neurofax EEG-1100 (Nihon Kohden, Япония);

- исследование мозгового кровотока методом ультразвукового дуплексного сканирования экстра- и интракраниальных отделов магистральных артерий головы и шеи на приборе Philips EnVisor (PHILIPS);

- электрокардиографию с оценкой вариабельности ритма сердца с помощью аппарата Schiller AT-10 plus (Германия).

Все больные получали Корвитин ${ }^{\circledR}$ (лиофилизат для приготовления раствора для инъекций (комплекс кверцетина с повидоном) производства ПАО НПЦ «Борщаговский ХФЗ») в дозе 0,5 г в сутки в течение 10 дней. Для приготовления раствора для внутривенного введения препарат растворяли в 100 мл изотонического раствора $\mathrm{NaCl}$ и вводили внутривенно капельно в течение 15-20 минут 1 раз в день.

Статистическую обработку данных проводили с помощью программного обеспечения Statistica 6,0. Рассчитывали среднее значение, ошибку среднего и статистическую значимость c помощью параметрического (t-критерий Стьюдента) и непараметрического ( $\chi^{2}$ Пирсона) методов. 
Оригінальні дослідження

\section{Результаты и обсуждение}

Анализ динамики общего состояния больных показал, что под влиянием курсового приема Корвитина уменьшились жалобы на головные боли у 80,0\% больных, на головокружение у $70,0 \%$, на боли в области сердца - у 80,0\%, у 70,0\% больных нормализовался сон. У больных ИИ отмечено повышение физической активности: индекс Бартел до лечения со-

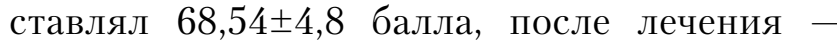
$74,26 \pm 3,6$ балла.

У больных ИИ после курсового приема Корвитина достоверно улучшились функции кратковременной и долгосрочной вербальной памяти (по данным теста «Запоминание 10 слов» А.Р. Лурия). Так, до лечения кверцетином по максимальному количеству запомненных слов и суммарному количеству слов за 5 предъявлений умеренные нарушения кратковременной памяти наблюдались в 53,3\% случаев, выраженные нарушения - в 23,3\%, и только в 23,3\% случаев не выявлено нарушений кратковременной памяти. После лечения данным препаратом выраженных нарушений не наблюдалось, а нормальная кратковременная память у больных ИИ отмечалась в 2 раза чаще, чем до лечения.

По результатам исследования долгосрочной памяти по показателям отставленного воспроизведения, до лечения нормальные значения отмечались в 23,3\% случаев, после лечения в $66,7 \%$ случаев, количество больных с умеренными нарушениями уменьшилось с 43,3\% до $26,7 \%$, а с выраженными - с 33,3\% до 6,7\%.

У больных ИИ после курсового приема Корвитина достоверно улучшилась избирательность внимания по тесту Мюнстерберга. Так, количество больных с нормальной устойчивостью внимания после лечения увеличилось практи-

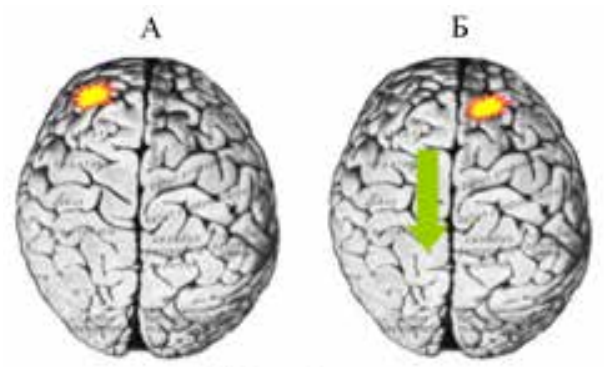

Дельта-ритм чески на 20\%, а с выраженными нарушениями внимания - уменьшилась в 2 раза.

Таким образом, у больных с ИИ Корвитин ${ }^{\circledR}$ активирует кратко- и долгосрочную память, повышает уровень внимания.

Для оценки механизмов, определяющих влияние Корвитина на психоэмоциональные и мнестические функции у больных ИИ, был проведен комплексный анализ функционального состояния мозга по структуре его биоэлектрической активности и показателям мозгового кровотока.

Установлено, что под влиянием Корвитина у больных ИИ происходит реорганизация структуры биоэлектрической активности головного мозга. Тип этой реорганизации имеет полушарные особенности. У больных с левополушарной (ЛП) локализацией ИО (ишемического очага) в центральных областях пораженного и интактного полушарий снижается мощность тетаи дельта-ритмов. Однако достоверное снижение мощности тета-ритма отмечается в центральных областях интактного полушария, а мощности в диапазоне дельта-ритма - в лобной области интактного полушария и в височной области пораженного полушария. У больных с правополушарным (ПП) инсультом под влиянием кверцетина достоверно снижается мощность тета-ритма только в височной области правого полушария (рис. 1, табл. 1-2).

Основным пейсмекером тета-ритма является гипокамп, и снижение мощности этого ритма в отдельных областях мозга под влиянием кверцетина в определенной степени свидетельствует о повышении функциональной активности гиппокампальных структур [5].

С учетом того, что альфа-ритм является базисным ритмом биоэлектрической активности головного мозга и характеризует функциональное состояние таламо-кортикальных структур
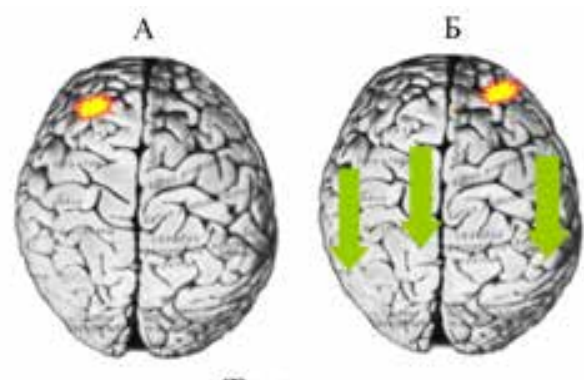

Тета-ритм

Рис. 1. Динамика мощности медленных ритмов электроэнцефалограммы у больных ишемическим инсультом под влиянием кверцетина: А — правополушарный инсульт, Б - левополушарный инсульт. 
Таблица 1. Характеристика интенсивности дельта-ритма у пациентов с ишемическим инсультом до и после лечения кверцетином

\begin{tabular}{|c|c|c|c|c|c|}
\hline \multirow{2}{*}{$\begin{array}{l}\text { Область } \\
\text { мозга }\end{array}$} & & \multicolumn{2}{|c|}{ ЛП инсульт } & \multicolumn{2}{|c|}{ ПП инсульт } \\
\hline & & $\begin{array}{l}\text { до } \\
\text { лечения }\end{array}$ & $\begin{array}{l}\text { после } \\
\text { лечения }\end{array}$ & $\begin{array}{l}\text { до } \\
\text { лечения }\end{array}$ & $\begin{array}{l}\text { после } \\
\text { лечения }\end{array}$ \\
\hline \multirow[t]{2}{*}{ Лоб } & 1 & $0,87 \pm 0,14$ & $0,71 \pm 0,14$ & $0,77 \pm 0,07$ & $0,74 \pm 0,07$ \\
\hline & 2 & $0,59 \pm 0,06$ & $0,58 \pm 0,1$ & $0,78 \pm 0,07$ & $0,81 \pm 0,09$ \\
\hline \multirow[t]{2}{*}{ Центр } & 1 & $0,91 \pm 0,14$ & $0,78 \pm 0,15$ & $0,77 \pm 0,07$ & $0,67 \pm 0,05$ \\
\hline & 2 & $0,70 \pm 0,05$ & $0,56 \pm 0,08^{*}$ & $0,85 \pm 0,08$ & $0,81 \pm 0,08$ \\
\hline \multirow[t]{2}{*}{ Затылок } & 1 & $0,63 \pm 0,09$ & $0,56 \pm 0,09$ & $0,67 \pm 0,06$ & $0,63 \pm 0,09$ \\
\hline & 2 & $0,55 \pm 0,05$ & $0,51 \pm 0,06$ & $0,73 \pm 0,06$ & $0,72 \pm 0,08$ \\
\hline \multirow[t]{2}{*}{ Висок } & 1 & $0,82 \pm 0,14$ & $0,73 \pm 0,12$ & $0,74 \pm 0,08$ & $0,68 \pm 0,06$ \\
\hline & 2 & $0,61 \pm 0,06$ & $0,58 \pm 0,08$ & $0,85 \pm 0,07$ & $0,76 \pm 0,09$ \\
\hline
\end{tabular}

таблица 2. Характеристика интенсивности тета-ритма у пациентов с ишемическим инсультом до и после лечения кверцетином

\begin{tabular}{llllll}
\hline Область & \multicolumn{2}{l}{ лП инсульт } & \multicolumn{2}{l}{ ПП инсульт } \\
\cline { 2 - 6 } мозга & до & после & до & после \\
& лечения & лечения & лечения & лечения \\
\hline Лоб & 1 & $1,13 \pm 0,16$ & $0,99 \pm 0,15$ & $1,12 \pm 0,19$ & $0,93 \pm 0,14$ \\
& 2 & $1,12 \pm 0,08$ & $0,8 \pm 0,09^{*}$ & $1,06 \pm 0,13$ & $1,1 \pm 0,2$ \\
Центр & 1 & $1,31 \pm 0,11$ & $1,11 \pm 0,11$ & $1,19 \pm 0,18$ & $1,03 \pm 0,15$ \\
& 2 & $1,18 \pm 0,12$ & $0,92 \pm 0,1$ & $1,27 \pm 0,17$ & $1,31 \pm 0,2$ \\
Затылок & 1 & $0,89 \pm 0,13$ & $0,85 \pm 0,14$ & $0,95 \pm 0,17$ & $0,86 \pm 0,21$ \\
& 2 & $0,85 \pm 0,14$ & $0,74 \pm 0,11$ & $1,01 \pm 0,11$ & $1,02 \pm 0,18$ \\
Висок & 1 & $1,26 \pm 0,11$ & $1,04 \pm 0,08^{*}$ & $1,14 \pm 0,22$ & $0,97 \pm 0,16$ \\
& 2 & $1,1 \pm 0,12$ & $0,89 \pm 0,1$ & $1,29 \pm 0,08$ & $1,07 \pm 0,09^{*}$ \\
\hline
\end{tabular}

Примечание: * - достоверная разница с показателем до лечения.

мозга, особый акцент при анализе влияния кверцетина на биоэлектрическую активность мозга сделан на анализе этого ритма. Установлено, что у больных ИИ с локализацией ИО в левом полушарии под влиянием Корвитина достоверно увеличивается мощность в диапазоне альфа-1ритма в центральной, затылочной и височной областях обоих полушарий и в лобной области интактного полушария, мощность альфа-2- таблица 3. Характеристика интенсивности альфа-1-ритма у пациентов с ишемическим инсультом до и после лечения кверцетином

\begin{tabular}{llllll}
\hline Область & \multicolumn{2}{l}{ лП инсульт } & \multicolumn{2}{l}{ ПП инсульт } \\
\cline { 2 - 6 } & & после & до & после & до \\
& 1 & $1,15 \pm 0,23$ & $1,29 \pm 0,19$ & $1,2 \pm 0,15$ & $1,32 \pm 0,14$ \\
\hline Лоб & 2 & $1,12 \pm 0,11^{*}$ & $1,37 \pm 0,11$ & $1,31 \pm 0,16$ & $1,41 \pm 0,15$ \\
Центр & 1 & $1,41 \pm 0,18^{*}$ & $1,73 \pm 0,12$ & $1,4 \pm 0,12^{*}$ & $1,69 \pm 0,11$ \\
& 2 & $1,39 \pm 0,17^{*}$ & $1,72 \pm 0,12$ & $1,57 \pm 0,2$ & $1,74 \pm 0,2$ \\
Затылок & 1 & $1,12 \pm 0,13^{*}$ & $1,45 \pm 0,17$ & $1,19 \pm 0,12^{*}$ & $1,5 \pm 0,15$ \\
& 2 & $1,04 \pm 0,17^{*}$ & $1,59 \pm 0,18$ & $1,47 \pm 0,21$ & $1,46 \pm 0,15$ \\
Висок & 1 & $1,4 \pm 0,12^{*}$ & $2,07 \pm 0,19$ & $1,39 \pm 0,22^{*}$ & $2,1 \pm 0,25$ \\
& 2 & $1,38 \pm 0,17^{*}$ & $2,14 \pm 0,11$ & $1,68 \pm 0,24$ & $1,94 \pm 0,19$ \\
\hline
\end{tabular}

Примечание: * - достоверная разница с показателем до лечения.

таблица 4. Характеристика интенсивности альфа-2 -ритма у пациентов с ишемическим инсультом до и после лечения кверцетином

\begin{tabular}{|c|c|c|c|c|c|}
\hline \multirow{2}{*}{$\begin{array}{l}\text { Область } \\
\text { мозга }\end{array}$} & & \multicolumn{2}{|l|}{ ЛП инсульт } & \multicolumn{2}{|c|}{ ПП инсульт } \\
\hline & & $\begin{array}{l}\text { после } \\
\text { лечения }\end{array}$ & $\begin{array}{l}\text { до } \\
\text { лечения }\end{array}$ & $\begin{array}{l}\text { после } \\
\text { лечения }\end{array}$ & $\begin{array}{l}\text { до } \\
\text { лечения }\end{array}$ \\
\hline \multirow[t]{2}{*}{ Лоб } & 1 & $0,54 \pm 0,07^{*}$ & $0,71 \pm 0,06$ & $0,73 \pm 0,09$ & $0,79 \pm 0,07$ \\
\hline & 2 & $0,56 \pm 0,05$ & $0,62 \pm 0,06$ & $0,79 \pm 0,12$ & $0,74 \pm 0,07$ \\
\hline \multirow[t]{2}{*}{ Центр } & 1 & $0,68 \pm 0,13$ & $0,87 \pm 0,07$ & $0,92 \pm 0,07$ & $0,95 \pm 0,06$ \\
\hline & 2 & $0,7 \pm 0,08$ & $0,84 \pm 0,07$ & $1,09 \pm 0,15$ & $0,98 \pm 0,07$ \\
\hline \multirow[t]{2}{*}{ Затылок } & 1 & $0,64 \pm 0,14$ & $0,67 \pm 0,06$ & $0,86 \pm 0,12$ & $0,86 \pm 0,08$ \\
\hline & 2 & $0,73 \pm 0,12$ & $0,8 \pm 0,08$ & $1 \pm 0,15$ & $0,88 \pm 0,07$ \\
\hline \multirow[t]{2}{*}{ Висок } & 1 & $0,79 \pm 0,19$ & $0,91 \pm 0,07$ & $1,02 \pm 0,11$ & $1,05 \pm 0,1$ \\
\hline & 2 & $0,87 \pm 0,15$ & $1,01 \pm 0,1$ & $1,29 \pm 0,19$ & $1,16 \pm 0,1$ \\
\hline
\end{tabular}

Примечание: * - достоверная разница с показателем до лечения.

ритма увеличивается только в лобной области пораженного полушария. У больных ИИ с локализацией ИО в правом полушарии Корвитин ${ }^{\circledR}$ достоверно увеличивал мощность в диапазоне альфа-1-ритма в центральной, затылочной и височной областях интактного полушария (рис. 2, табл. 3-4). Как известно, повышение мощности альфа-ритма свидетельствует об усилении тормозных процессов [6].

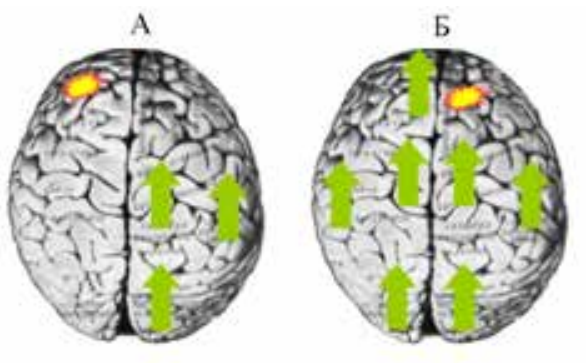

Альфа-1-ритм
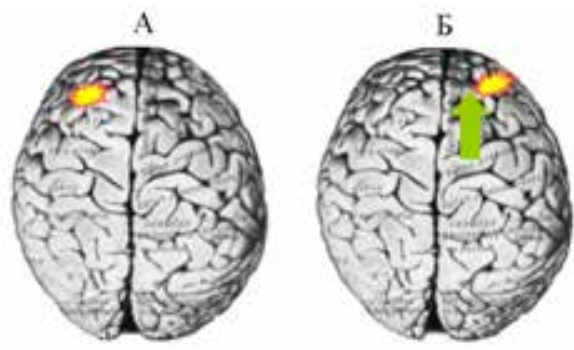

Альфа-2-ритм

Рис. 2. Динамика мощности альфа-ритма у больных ИИ под влиянием кверцетина: А 一 правополушарный инсульт, Б - левополушарный инсульт. 
У больных с локализацией ИО в правом и левом полушарии кверцетин не вызывал достоверных изменений биоэлектрической активности головного мозга в диапазоне бета-ритмов, отмечена только тенденция к снижению мощности бета-1-ритма.

У больных, перенесших ИИ, кверцетин увеличивал частоту альфа-ритма. Мозаика частотного увеличения альфа-ритма также определяется полушарной локализацией ИО. Так, у больных с локализацией ИО в левом полушарии увеличивалась частота альфа-ритма в центральных областях интактного полушария, у больных с правополушарным инсультом - в затылочной области левого полушария и в двух височных областях (табл. 5).

Систематизируя данные о влиянии кверцетина на структуру биоэлектрической активности головного мозга, следует отметить, что у больных с локализацией ИО в левом полушарии активнее происходит положительная реорганизация биоэлектрической активности головного мозга преимущественно в диапазоне медленных ритмов, а у больных с правополушарным инсультом - в диапазоне альфа-ритма, что, вероятно, обусловлено функционально-биохимической асимметрией мозга [2].

Кверцетин у больных ИИ оказывает и вазоактивное действие. Так, у больных с локализацией ИО в левом полушарии под влиянием кверцетина увеличивалась линейная систолическая скорость кровотока (ЛССК) в сосудах пораженного полушария во внутренней сонной артерии (BCA) в интактном полушарии, в левой позвоночной артерии (ПА), средней мозговой артерии (CMA), задней мозговой артерии (ЗМА) и в базиллярной артерии (БА). У больных с правопо-

таблица 5. Характеристика мощности частоты альфа-ритма у пациентов с ишемическим инсультом до и после лечения кверцетином

\begin{tabular}{llllll}
\hline Область & \multicolumn{2}{l}{ лП инсульт } & \multicolumn{2}{l}{ ПП инсульт } \\
\cline { 2 - 6 } мозга & до & после & до & после \\
& & лечения & лечения & лечения & лечения \\
\hline Лоб & 1 & $9,2 \pm 0,41$ & $9,05 \pm 0,48$ & $9,65 \pm 0,24$ & $9,74 \pm 0,22$ \\
& 2 & $9,43 \pm 0,29$ & $9,62 \pm 0,38$ & $9,22 \pm 0,24$ & $9,28 \pm 0,19$ \\
Центр & 1 & $9,04 \pm 0,41$ & $9,05 \pm 0,49$ & $9,89 \pm 0,3$ & $10,2 \pm 0,29$ \\
& 2 & $9,43 \pm 0,28$ & $10,03 \pm 0,37$ & $9,45 \pm 0,28$ & $9,42 \pm 0,18$ \\
Затылок & 1 & $9,49 \pm 0,45$ & $9,4 \pm 0,39$ & $9,86 \pm 0,29$ & $10,51 \pm 0,3$ \\
& 2 & $9,88 \pm 0,29$ & $9,81 \pm 0,33$ & $9,48 \pm 0,28$ & $9,7 \pm 0,2$ \\
Висок & 1 & $9,08 \pm 0,41$ & $9,12 \pm 0,51$ & $9,73 \pm 0,29$ & $10,16 \pm 0,26$ \\
& 2 & $9,67 \pm 0,24$ & $9,83 \pm 0,31$ & $9,34 \pm 0,22$ & $9,81 \pm 0,15$ \\
\hline
\end{tabular}

лушарным инсультом в пораженном полушарии увеличивалась ЛССК в ПА, СМА, в интактном полушарии - в общей сонной артерии (ОСА), BCA, СМА (рис. 3).

Таким образом, у больных с левополушарным инсультом кверцетин увеличивает церебральный кровоток в отдельных сосудах каротидного и вертебро-базилярного бассейнов, у больных с правополушарным инсультом - преимущественно в каротидном бассейне и в правой ПА.

Об улучшении церебральной гемодинамики под влиянием кверцетина свидетельствует также достоверное снижение периферического сопротивления в отдельных сосудах каротидного и вертебро-базиллярного бассейнов. Так, у больных с локализацией ИО в левой гемисфере снижается индекс сопротивления (Ri) в правой и левой передних мозговых артериях (ПМА), ЗМА и БА; пульсационный индекс (Pi) в правой ВСА и в двух ПМА, 3МА (рис. 4).

Итак, у больных с левополушарным инсультом более широк диапазон сосудов, в которых под влиянием кверцетина достоверно снижается периферическое сопротивление (правая ВСА, левая ПА, правая и левая ПМА, правая и левая ЗМА, правая СМА, ОА), чем у больных с правополушарным инсультом (правая и левая СМА, левая ПА) - рис. 5 .

Таким образом, у больных с левополушарным инсультом кверцетин оказывает более выраженное влияние на структуру биоэлектрической активности головного мозга и церебральную гемодинамику, чем у больных с правополушарной локализацией ИО.

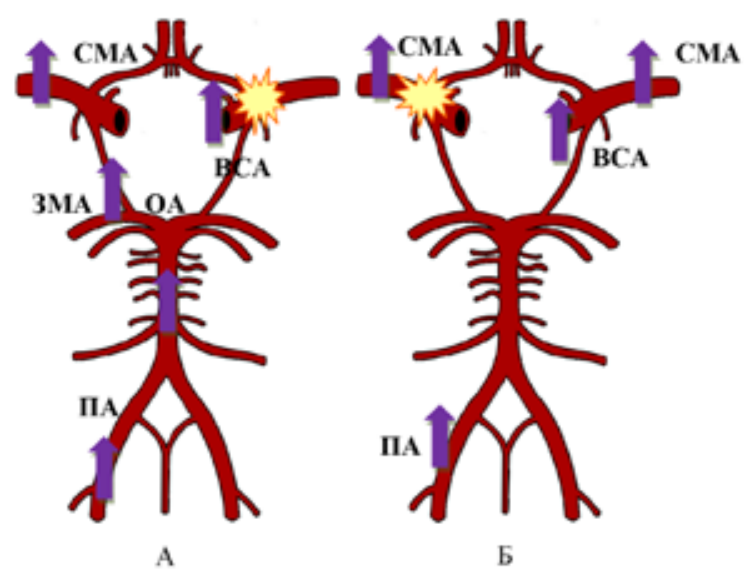

Рис. 3. Сравнительная характеристика ЛССК в сосудах каротидного и вертебро-базилярного бассейнов у больных с ишемическим инсультом до и после лечения кверцетином: А правополушарный инсульт, Б - левополушарный инсульт. 


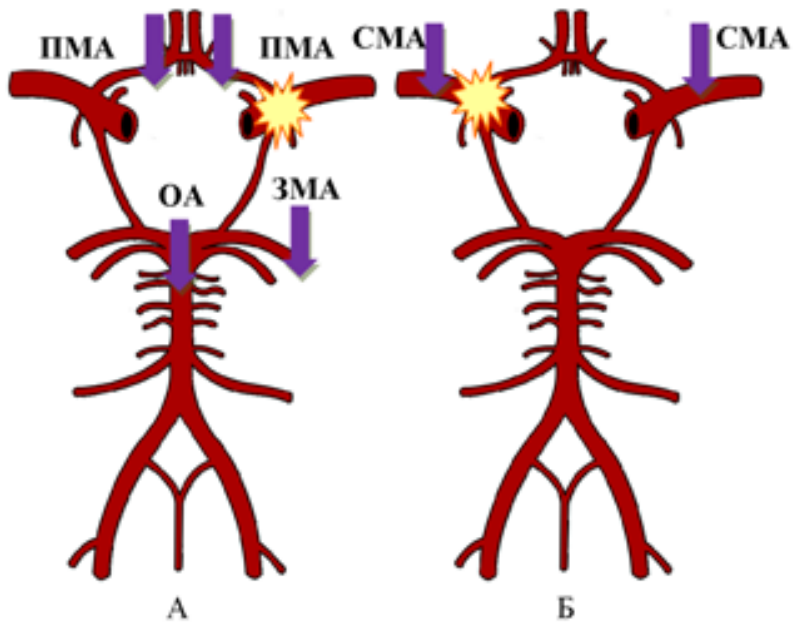

Рис. 4. Динамика индексов периферического сопротивления у больных ишемическим инсультом под влиянием кверцетина: А — правополушарный инсульт, Б - левополушарный инсульт.

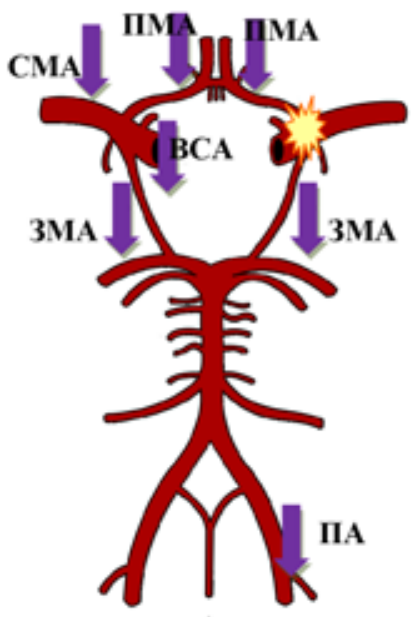

A

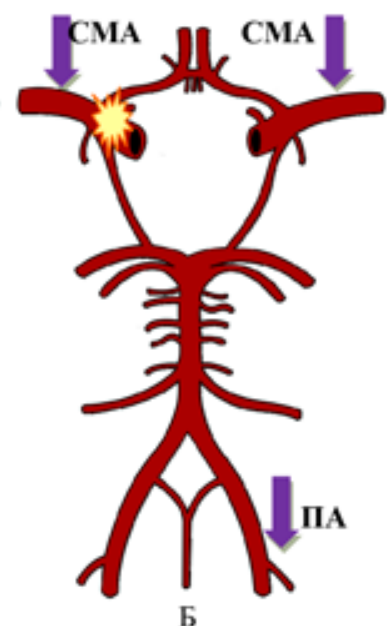

Б
Рис. 5. Динамика индексов эластичности у больных ИИ под влиянием кверцетина: А — правополушарный инсульт, Б - левополушарный инсульт.

Полушарные особенности влияния кверцетина на функциональное состояние мозга обусловлены тем, что левое полушарие «специализируется» на взаимодействии с трофотропными регуляторными системами, а правое - с эрготропными $[5,6]$.

В последние годы в нейрореабилитации больных инсультом активно внедряется исследование вариабельности ритма сердца, позволяющее определить состояние вегетативной нервной системы, риск развития кардиальной патологии и дать объективную характеристику адаптивному потенциалу постинсультных больных. Острое нарушение мозгового кровообращения приводит к изменениям автономной регуляции сердечно-сосудистой системы, нарушению вариабельности ритма сердца, повышению уровня катехоламинов в плазме крови и увеличению инцидентности кардиальных аритмий [5, 6]. Наиболее серьезным последствием этого каскада негативных реакций является увеличение вероятности внезапной смерти. За последние два десятилетия доказана существенная взаимосвязь между вегетативной нервной системой и смертностью от сердечно-сосудистых заболеваний, включая внезапную сердечную смерть. Экспериментальные подтверждения связи между предрасположенностью к летальным аритмиям и наличием признаков повышенной симпатической или пониженной вагусной активности стимулировали дальнейшие исследования количественных показателей обеспечения вегетативной регуляции. Вариабельность сердечного ритма (ВРС) - один из наиболее многообещающих показателей такого рода отражает колебания интервала между последовательными ударами сердца, а также колебания между последовательными частотами сердечных сокращений. Исследования ВРС при ИИ как предиктора риска внезапной сердечной смерти, в основном, ограничивались изучением влияния локализации очага поражения головного мозга на состояние вегетативной нервной системы. Так, показано, что вовлечение в поражение правого полушария головного мозга и, особенно, правого островка значительно увеличивает вероятность внезапной смерти [1, 5]. Кроме того, установлено, что нарушения ВРС (снижение) сочетаются с ишемическим повреждением левого островка, а также наблюдаются при ишемическом поражении среднего мозга. В других исследованиях обнаружена взаимосвязь нарушений ВРС с поражением корковых и подкорковых структур мозга, гипоталамуса, других центров вегетативной регуляции, включая связи миндалевидного ядра.

Для оценки влияния кверцентина на вегетативный статус проведен анализ ВРС до и после применения данного препарата. Для оценки вегетативного баланса рассчитывали временные и спектральныепоказатели ВРС. При анализе исходных данных до лечения кверцетином у больных ИИ отмечено снижение спектральных показателей, в частности, НЧ=508 117 (нормальное значение $-1170 \pm 416$ ) и ВЧ $=468 \pm 96$ (норма 975 203$)$, что может свидетельствовать о недо- 
статочной суммарной ВРС. Данное снижение общей ВРС может быть связано не только с ростом симпатической активности, но и со снижением всех вегетативных влияний на сердце. Необходимо отметить, что при этом показатель НЧ/ВЧ до лечения кверцетином был выше нормальных значений $(2,5 \pm 0,18$ при норме 1,5-2,0), что характерно для смещения симпато-парасимпатического баланса в сторону превалирования симпатического отдела центральной нервной системы и активации подкоркового симпатического центра. После лечения Корвитином у больных ИИ показатель НЧ/ВЧ нормализовался (НЧ/ВЧ=1,68 $\pm 0,18)$.

Под влиянием курсового приема кверцетина отмечено также изменение временной структуры ритма сердца: увеличивался триангулярный индекс, характеризующий общую мощность спектра и являющийся маркером парасимпатической активности ВНС (до лечения $-117 \pm 15$, после $-149 \pm 26)$. Данные изменения результатов спектрального и временного анализа ВРС свидетельствуют о гармонизации симпатико-парасимпатического баланса вегетативной нервной системы у данной категории больных после лечения Корвитином.

\section{Выводы}

1. У больных, перенесших ИИ, кверцетин улучшает психоэмоциональные и мнестические функции за счет положительной реорганизации биоэлектрической активности головного мозга, улучшения церебральной гемодинамики и гармонизации симпатического и парасимпатического звена вегетативной нервной системы.

2. Корригирующее влияние преперата Корвитин $^{\circledR}$ на функциональное состояние мозга и сердца дает основание рекомендовать применение препарата в системе реабилитации больных, перенесших ИИ.

\section{Список использованной литературы}

1. Барабой ВА. Биоантиоксиданты. Киев: Книга плюс. 2006. 461 с. (Baraboy VA. Bioantioxidants. Kiev: Knyha plyus. 2006;461p.).

2. Виничук СМ, Прокопив ММ, Черенько ТМ. Поиск новых подходов к лечению острого ишемического инсульта. Український неврологічний журнал. 2010; 1:8-19. (Vinichuk SM, Prokopiv MM Cheren'ko TM. Search for new approaches to the treatment of acute ischemic stroke. Ukrainsky Nevrologichnyi Zurnal. 2010;1:8-19).

3. Винничук СМ. Применение нового отечественного препарата Корвитин в лечении острого ишемического инсульта. Практична ангіологія. 2010;4(33):12-9. (Vinnichuk SM. The use of the new domestic drug Corvitin in the treatment of acute ischemic stroke. Practychna Angiologiya. 2010; 4(33):12-19).

4. Вірстюк ОА, Герасимчук РД. Клінічна ефективність комплексної терапії гострого ішемічного інсульту на тлі метаболічного синдрому із застосуванням препарату кверцетину «Корвітин». Український неврологічний журнал. 2011; 3: 18-29. (Virstyuk OA Gerasymchuk RD. Clinical efficacy of complex therapy of acute ischemic stroke against the background of metabolic syndrome with the use of the drug quercetin «Corvitin». Ukrainsky Nevrologichnyi Zurnal. 2011;3:18-29.

5. Гнездицкий ВВ. Обратная задача ЭЭГ и клиническая электроэнцефалография. Издательство Таганрогского государственного университета. 2000; 636 с. (Gnezditsky VV. The inverse problem of EEG and clinical electroencephalography. Izdatel'stvo Taganrogskogo Gosudarstvennogo Universiteta. 2000; 636 p.).

6. Гусев ЕИ, Скворцова ВИ. Ишемия головного мозга. М.: Медицина, 2001; 250 c. (Gusev EI, Skvortsova VI. Cerebral ischemia. M.: Meditsina, 2001; 250 p.)

7. Иванова ГЕ, Суворов АЮ, Медведева НМ, Дюдюкина ДВ, Лелюк ВГ. Фракция выброса левого желудочка при эхокардиографическом исследовании у больных с церебральным инсультом как предиктор реабилитационного прогноза. Материалы IV Международного конгресса «Нейрореабилитация 2012». 2012 49. (Ivanova GE, Suvorov AYu, Medvedeva NM, Dyudyukina DV, Lelyuk VG. Left ventricular ejection fraction in an echocardiographic study in patients with cerebral stroke as a predictor of rehabilitation prognosis. Materialy IV Mezhdunarodnogo Congressa «Neiroreabilitatsia 2012». 2012:49).

8. Констанадов ЭА, Черемушкин ЕА. Динамика индуцированной корковой активности. Журнал высшей нервной деятельности. 2012; 62 (3):311-21. (Konstanadov EA, Cheremushkin EA. Dynamics of induced cortical activity. Zhurnal Vystshey Nervnoy Deyatelnosti. 2012;62(3): 311-21).

9. Arakawa S, Perera N, Donnan GA. Neuroprotection in stroke. ACNR. 2005; 5(5):10-1.

10. Di Paolo G, De Camilli P. Phosphoinositides in cell regulation and membrane dynamics. Nature. 2006;12: 651-7.

(Надійшла до редакції 10.02.2020р.)

\section{Біофлавоноїди в лікуванні пацієнтів із цүкровим діабетом 2-го типу та церебральним атеросклерозом}

\section{М.Д. Тронько', С.М. Кузнецова², М.С. Черська'}

'ГУ «Інститут ендокринології та обміну речовин ім. В.П. Комісаренка НАМН України»

${ }^{2} Г У ~ «$ нститут геронтології ім. Д.Ф. Чеботарьова НАМН України»

Резюме. Мета роботи - комплексна оцінка впливу кверцетину на функціональний стан центральної нервової та серцевосудинної систем у хворих на ішемічний інсульт (II) та цукровий діабет 2-го типу (ЦД2) у відновлювальний період. Матеріал і методи. У клініці ДУ «ннститут геронтології ім. Д.Ф. Чеботарьова НАМН України» проведено відкрите пілотне когортне проспективне клінічне дослідження, що включало 30 хворих, які перенесли атеротромботичний ішемічний інсульт у каротидному басейні (19 жінок і 11 чоловіків), віком від 55 до 75 років (середній вік 64,3 7,5 року), третина з них мали в анамнезі ЦД2. Перед початком і після курсового приймання препарату кверцетин хворим проводили комплексне клініко-неврологічне та нейропсихологічне обстеження, дослідження мозкового кровобігу методом ультразвукового дуплексного сканування екстра- та інтракраніальних 
відділів магістральних артерій голови та шиї, електрокардіографію з оцінкою варіативності ритму серця. Усі хворі отримували кверцетин (ліофілізат для приготування розчину для ін'єкцій (комплекс кверцетину з повідоном), у дозі 0,5 г на добу протягом 10 днів. Для приготування розчину для внутрішньовенного введення препарат розчиняли в 100 мл ізотонічного розчину $\mathrm{NaCl}$ і вводили внутрішньовенно крапельно протягом 15-20 хвилин 1 раз на день.

Результати. У хворих із лівопівкульним інсультом кверцетин справляв більш виражений вплив на структуру біоелектричної активності головного мозку та церебральну гемодинаміку, ніж у хворих із правопівкульною локалізацією ІІ. У хворих, які перенесли II, кверцетин поліпшував психоемоційні та мнестичні функції за рахунок позитивної реорганізації біоелектричної активності головного мозку, поліпшення церебральної гемодинаміки та гармонізації симпатичної та парасимпатичної ланок вегетативної нервової системи. Висновки. Коригуючий вплив кверцетину на функціональний стан мозку та серця дає підставу рекомендувати застосування препарату в системі реабілітації хворих, які перенесли ішемічний інсульт.

Ключові слова: ішемічний інсульт, цукровий діабет 2-го типу, функціональний стан нервової та серцево-судинної систем, кверцетин.

\section{Bioflavonoids in the treatment of patients with type 2 diabetes mellitus and cerebral atherosclerosis}

\section{M.D. Tronko, S.M. Kuznetsova, M.S. Cherska}

' SI «V.P. Komissarenko Institute of Endocrinology and Metabolism of NAMS of Ukraine», Kyiv, Ukraine

${ }^{2} \mathrm{SI}$ «D.F. Chebotarev Institute of Gerontology of NAMS of Ukraine», Kyiv, Ukraine

Abstract. The purpose of the work was a comprehensive assessment of the effect of quercetin on the functional state of the central nervous and cardiovascular system in patients with ischemic stroke (II) and type 2 diabetes mellitus in the recovery period. Material and methods. In the clinic of the State Institution «D.F. Chebotarev Institute of Gerontology of NAMS of Ukraine» conducted an open pilot cohort prospective clinical study, which included 30 patients who had an atherothrombotic ischemic stroke in the carotid pool ( 19 women, 11 men) aged 55 to 75 years (average age $64.3 \pm 7.5$ years), $30 \%$ had a history of type 2 diabetes. Before and after course administration of quercetin, patients underwent a comprehensive clinical, neurological and neuropsychological examination, a study of cerebral blood flow using ultrasound duplex scanning of extra- and intracranial sections of the main arteries of the head and neck, electrocardiography with an assessment of heart rate variability. All patients received quercetin (lyophilisate for the preparation of an injection solution (complex of quercetin with povidone), at the dose of $0.5 \mathrm{~g}$ per day for 10 days. To prepare a solution for intravenous administration, the drug was dissolved in $100 \mathrm{ml}$ of an isotonic solution $\mathrm{NaCl}$ and was administered intravenously drip for 15-20 minutes 1 time per day. Results. The article presents the results of a comprehensive assessment of the impact of the drug quercetin on functional condition of the central nervous and cardiovascular system in patients with diabetes mellitus and ischemic stroke in the recovery stroke period. In patients with left-hemispheric stroke quercetin has more pronounced effect on the structure of the bioelectrical activity of the brain and cerebral hemodynamics than in patients with right-hemisphere localization of ischemic stroke. Patients undergoing ischemic stroke quercetin improves psycho-emotional and mnemonic function by positive reorganization of bioelectrical activity of the brain, improve cerebral hemodynamics and harmonization of the sympathetic and parasympathetic autonomic nervous system. Conclusion. Quercetin's corrective influence on the functional state of the brain and the heart gives reason to recommend this drug in the system of rehabilitation of patients after ischemic stroke.

Keywords: ischemic stroke, type 2 diabetes mellitus, functional state of the nervous and cardiovascular system, quercetin. 